\title{
EDUCAÇÃO AMBIENTAL NA EDUCAÇÃO INFANTIL E PROPRIEDADES RURAIS PEDAGÓGICAS: POTENCIALIDADES E DESAFIOS
}

\author{
Angela Luciane Klein ${ }^{1}$; Sônia Maria Marchiorato Carneiro²
}

\section{RESUMO}

O presente trabalho visa a socializar questões teórico-metodológicas de Tese em desenvolvimento, acerca das potencialidades e desafios da Educação Ambiental (EA) na Educação Infantil (EI), em conexão com Propriedades Rurais Pedagógicas. A pesquisa, de caráter qualitativo, sob a modalidade da Pesquisa-Ação Colaborativa, com professoras da EI de Joinville, SC, envolveu inicialmente a realização de um estudo exploratório em quatro Centros de EI deste município, para verificar a ação pedagógico-didática de professoras da $\mathrm{El}$, quanto à EA nas Propriedades Rurais Pedagógicas. Constatou-se a necessidade dessas docentes repensarem as atividades nas Propriedades Rurais Pedagógicas, em conexão com a EA; e também se evidenciaram fragilidades e lacunas da prática da $E A$, especialmente quanto à formação socioambiental cidadã das crianças, reforçando a demanda de uma práxis pedagógica para a transformação da realidade socioeducativa escolar.

Palavras-chave: Educação Ambiental; Educação Infantil; Propriedades Rurais Pedagógicas.

\section{ENVIRONMENTAL EDUCATION IN CHILDREN EDUCATION IN CONNECTION WITH FARMS EDUCATION: POTENTIALITIES AND CHALLENGES}

\section{ABSTRACT}

The present work aims to explain theoretical and methodological issues of the thesis in developing. This thesis is based on the potentialities and challenges of Environmental Education in Children Education in connection with Farms Education. The research, using qualitative methodology, is performed under the Research-Action Collaborative program with teachers from the Children Education of Joinville-SC. This research started with a exploratory study involving four Children Education Centers in the city, in order to verify the pedagogical action of the teachers in the Children Education regarding the Environmental Education in the Farms Education From it, the following problems have been detected: the need of these teachers to rethink the activities in the Farms Education based on the Environmental Education;

1 Doutoranda no Programa de Pós-Graduação em Educação da Universidade Federal do Paraná. E-mail: angelaklain@yahoo.com.br.

2 Doutora em Meio Ambiente e Desenvolvimento; professora do Programa de Pós-Graduação em Educação da Universidade Federal do Paraná. E-mail: carneiro.sonmaria@gmail.com. 
and the weaknesses and gaps in the practice of Environmental Education, especially regarding the social and environmental formation of the children. The last one is demanded for a pedagogical praxis leading the transformation of the socio-educational reality of the school.

Keywords: Environmental Education; Children Education; Farms Education.

\section{Introdução}

Os problemas socioambientais em nosso Planeta reforçam a relevância da dimensão ambiental da Educação, a qual deve estar presente em todas as etapas de ensino, desde a El, em vista da formação socioambiental cidadã das crianças. Segundo Carneiro (1999, p. 04), "[...] trata-se de afirmar as práticas de educação ambiental como integrantes do processo educativo escolar, dado que a Educação Ambiental não constitui um tipo especial de educação, nem pode ser reduzida a uma disciplina curricular", ou ainda, conforme Sauvé (2005, p. 317), “[...] uma "ferramenta" para a resolução de problemas ou de gestão do meio ambiente [...]".

Nessa perspectiva, a EA emerge como prática sócio-pedagógica reflexiva e crítica que "[...] tem o mundo, a realidade-ambiente, como mediador do processo educativo [...]" (DICKMANN, 2015, p. 77); uma "[...] atividade intencional da prática social, que deve imprimir ao desenvolvimento individual um caráter social em sua relação com a natureza e com os outros seres humanos" (BRASIL, 2012); uma prática integrada às realidades socioambientais dos sujeitos e permeada por ações, diálogos e saberes de caráter transdisciplinar, rompendo a fragmentação do conhecimento, tão presente em nossas escolas; uma EA responsável e comprometida com a formação humana e cidadã e com a sustentabilidade da vida.

Nesse contexto, cabe à El enquanto primeira etapa da Educação Básica, introduzir a EA para que as crianças possam ser "[...] estimuladas a construir conhecimentos acerca dos temas socioambientais com intuito de se superar o senso comum, a desenvolver capacidades de se sensibilizar, compreender e repensar a problemática socioambiental [...]" (SAHEB, 2016, p. 145). Para tal, torna-se necessário reconhecer as crianças como sujeitos históricos e de direitos que constroem sua identidade pessoal e coletiva por meio das interações, relações e práticas vivenciadas nos diferentes espaços de 
convivência (BRASIL, 2010), percebendo-as como seres humanos que se vão desenvolvendo cotidianamente, com curiosidade e interesse pela exploração de objetos e atividades que possibilitem experiências interativas com os ambientes de vida, na relação com adultos, outras crianças e seres não humanos (ABREU, 2017).

A partir dessa compreensão sobre a criança, torna-se igualmente importante pensar sobre os espaços da $\mathrm{El}$, que não se devem limitar às salas de atividades, em ambientes fechados. Para Tiriba (2007; 2010), as atividades ao ar livre, com experiências de contato com a natureza, são fundamentais ao desenvolvimento da criança e, portanto, à El. Segundo a autora, as propostas educativas para a primeira infância requerem "[...] rotinas que não fragmentem o sentir e o pensar, que estejam atentas às vontades do corpo, que não aprisionem os movimentos" (TIRIBA, 2007, p. 223). A criança aprende brincando, interagindo, sentindo e experimentando. Assim, "[...] quanto mais oportunidades ela tiver de experimentar, tocar, sentir, maiores serão as chances de perceber-se como um ser integrante, dependente e transformador do mundo em que está inserido" (KLEIN, 2007, p. 32).

$\mathrm{Na}$ busca de respostas a essas questões, novos espaços educativos começam a surgir, ganhando visibilidade no campo da educação formal, favorecendo novos olhares e novas propostas educativas. Espaços que outrora eram vistos como locais sem qualquer função educativa, no cenário atual têm emergido como verdadeiros laboratórios de ensino e aprendizagem ao ar livre, permitindo às crianças experiências que nem sempre são possíveis no ambiente escolar ou em seus lares, a exemplo das Propriedades Rurais Pedagógicas. Há cerca de duas décadas, as propriedades das famílias rurais, com produção agrícola e pecuária, passaram a receber um novo foco, educativo e ambiental - na medida em que seus proprietários abriram as portas a grupos de estudantes de diferentes faixas etárias, a fim de mostrar os fazeres e saberes do homem do campo.

Sob esses pressupostos, o presente trabalho visa a socializar a Tese ${ }^{3}$, em desenvolvimento, acerca da EA na El em conexão com as Propriedades

\footnotetext{
3 Doutorado (turma 2017) em andamento no Programa de Pós-Graduação em Educação da Universidade Federal Paraná, na linha de pesquisa Cultura, Escola e Ensino, sob a orientação da professora Dra. Sônia Maria Marchiorato Carneiro.
} 
Rurais Pedagógicas. Trata-se de uma pesquisa de caráter qualitativo, sob a modalidade da Pesquisa-Ação Colaborativa, com professoras da El do município de Joinville, SC. Com base na questão da pesquisa: - "Como promover uma Educação Ambiental sob a perspectiva da formação socioambiental cidadã das crianças na Educação Infantil, a partir das experiências vivenciadas nas Propriedades Rurais Pedagógicas?", realizou-se no segundo semestre de 2017, um estudo exploratório envolvendo quatro Centros de Educação Infantil localizados na cidade de Joinville, com o objetivo de verificar a ação pedagógico-didática das professoras da Educação Infantil durante as visitas a Propriedades Rurais Pedagógicas, situados no respectivo município.

Na sequência, apresenta-se breve contextualização e caracterização das Propriedades Rurais Pedagógicas, com destaque aos resultados de duas pesquisas em nível de Especialização e Mestrado; e depois, a descrição da metodologia da pesquisa de campo da Tese, com ênfase no estudo exploratório, realizado no segundo semestre de 2017, em quatro centros de Educação Infantil de Joinville. Por fim, elucidam-se as principais potencialidades e desafios da EA na El, em conexão com as Propriedades Rurais Pedagógicas e as possíveis contribuições do referido estudo ao campo da EA.

\section{Propriedades Rurais Pedagógicas: contextualização, caracterização e resultados de pesquisas}

Embora pouco conhecidas e pesquisadas no cenário brasileiro, as Propriedades Rurais Pedagógicas ${ }^{4}$ já são objetos de estudo em países europeus, como França, Finlândia, Itália, Holanda, Noruega e Portugal; e ainda, Estados Unidos, Chile e Japão. Nesses países, as atividades pedagógicas em propriedades rurais vêm-se destacando em forma de projetos de cooperação entre as escolas e a educação básica - evidenciando a

\footnotetext{
${ }^{4}$ Conforme pesquisas realizadas, o termo Propriedade Rural Pedagógica difere de um país para outro, conforme o idioma: na França utiliza-se o vocábulo fermes pédagogiques; na Itália, fattorie didattiche; em Portugal, quintas pedagógicas; no Chile, granjas educativas. Na Noruega, o termo green care tem se difundido de modo significativo nos últimos anos, assim como a expressão the farm as a pedagogical resource. Nos Estados Unidos e no Japão, utilizam-se as expressões farms-to-school e/ou farms educational (KLEIN, 2012).
} 
importância desses espaços nos processos de ensino e de aprendizagem, com ênfase em questões ambientais (KLEIN, 2012).

Nesse cenário promissor, destacam-se as experiências italianas, francesas e norueguesas, as quais trazem informações relevantes sobre as características e as potencialidades educativas das atividades desenvolvidas no âmbito das Propriedades Rurais Pedagógicas. Na Itália, a exploração pedagógica desse tipo de propriedade contribuiu para a elaboração de um documento assinado em 2001, entre a Confederação Italiana dos Agricultores (CIA) e o Ministério da Educação da Itália, visando ao desenvolvimento de um projeto denominado "Escolas na Propriedade Rural", com o propósito de aproximar as crianças e jovens ao universo rural. Nesse acordo, determinou-se um conjunto de princípios e deveres a serem assumidos pela referida Confederação, como a organização de uma rede nacional de escolas em conexão com as propriedades rurais; a elaboração de uma carta orientadora da qualidade de práticas educativas nas propriedades; o desenvolvimento de cursos de formação para os agricultores; a preparação de materiais didáticos; e proposta formativa aos docentes (FRANCO; SENNI, 2005). A partir dessa iniciativa, muitas regiões italianas passaram a adotar as cartas de qualidade, com o intuito de desenvolver práticas educativas adequadas nas Propriedades Rurais Pedagógicas. Apesar das especificidades de cada região, as cartas contemplam um conjunto de regulamentos semelhantes, relacionados com segurança e higiene, características estruturais e de produção das propriedades, formação de competências dos agricultores, proposta didática, bem como organização e logística (BAMBI; TEI; BARBARI, 2009).

Outro país que promulgou documentos em prol das Propriedades Rurais Pedagógicas foi a França. De acordo com Caffarelli et al. (2010), em 2001 uma comissão interministerial (Ministério da Educação Nacional; da Agricultura e Pesca; do Desenvolvimento Territorial e Ambiental; da Juventude e dos Esportes; da Justiça) publicou uma Circular definindo as características das estruturas das propriedades rurais pedagógicas e o papel delas, bem como os objetivos e os tipos de públicos. Conforme esse documento, a propriedade rural pedagógica caracteriza-se pela criação de animais, ou culturas agrícolas e recebe crianças e jovens de escolas e fora delas, podendo ser de dois tipos: propriedades de animação, localizadas em áreas urbanas e periburbanas, com 
pouca ou nenhuma produção agrícola, mas dispondo de uma diversidade de animais domésticos; e as propriedades propriamente rurais - além de manter sua função primária de produção, também desenvolvem atividades educativas recebendo crianças e jovens de maneira regular.

$\mathrm{Na}$ Noruega, a compreensão do relevante papel desempenhado pelas propriedades rurais, no âmbito da educação, é evidenciada a partir dos projetos de cooperação entre propriedades rurais e escolas que, desde 1995, vêm desenvolvendo e expandido essa proposta. Nesta época, com a assistência da Universidade Norueguesa de Ciências da Vida (UMB), foi desenvolvido o projeto inicial Living School, em oito escolas e oito propriedades rurais, com o propósito principal de promover atividades pedagógicas que possibilitassem aos estudantes um conjunto de experiências de interação com o ambiente rural e natural. O projeto também contou com o apoio do governo norueguês que, por meio dos Ministérios da Educação e da Agricultura, concedeu ao projeto a quantia de um milhão de euros. No período, as escolas passavam por um processo de reformulação curricular e a proposta de projetos contemplava o desenvolvimento de atividades práticas em espaços fora da sala de aula - o que contribuiu para o sucesso do projeto Living School (JOLLY et al., 2004).

As potencialidades desses espaços sócio-pedagógicos tornaram-se, assim, foco de estudos de pesquisadores que buscaram elucidar relações entre escolas e propriedades rurais. Segundo Nasolini (2005), as atividades desenvolvidas no âmbito das propriedades rurais são orientadas por três ideias básicas. A primeira está relacionada a uma pedagogia ativa, do aprenderfazendo, representada por um conjunto diversificado de atividades práticas e experiências concretas; a segunda, refere-se ao contato direto com animais e plantas em seu ambiente natural; e a terceira compreende a oportunidade de encontro e interação entre agricultores e jovens, possibilitando-Ihes o enriquecimento de experiências.

Ainda, conforme Campos (2010), as Propriedades Rurais Pedagógicas compreendem ambientes que podem contribuir para a formação e desenvolvimento de crianças e jovens, quanto a valores do meio rural a partir das práticas agrícolas, pecuárias e artesanais. Consequentemente, esses espaços tornam-se ambientes pedagógicos valiosos, possibilitando a 
experiência pessoal de vivenciar e descobrir novas sensações e emoções, que acabam despertando um sentimento de pertencimento e de inter-relação com esses ambientes de vida (KLEIN; TROIAN; SOUZA, 2011). Portanto, as Propriedades Rurais Pedagógicas tornam-se um instrumento de conexão entre campo e cidade e de comunicação entre agricultores e estudantes, numa relação favorável para conservar o patrimônio sociocultural e agroalimentar; e também de respeito ao meio ambiente, na medida em que as propriedades rurais devem ser exemplo de sustentabilidade socioambiental (GURRIERI, 2008).

A relevância atribuída às Propriedades Rurais Pedagógicas, enquanto espaços com potencial para a promoção da EA, é ressaltada não apenas em pesquisas envolvendo experiências internacionais, mas também no cenário brasileiro, com destaque a dois estudos nos anos de 2007 e 2012 . O primeiro estudo $^{5}$ analisou as ações pedagógicas em EA para a EI, na Fazenda Quinta da Estância Grande, uma Propriedade Rural Pedagógica localizada no município de Viamão, RS, que desenvolve atividades educativas para grupos escolares desde 1992. A análise dos dados coletados $^{6}$ revelaram que as atividades desenvolvidas com as turmas de El possibilitavam às crianças diferentes vivências em contato com a natureza, favorecendo-lhes a investigação e a experimentação, em situações reais e instigando-as à curiosidade, além de oportunizar experiências que estimulavam seus sentidos (KLEIN, 2007).

O caráter valorativo desse tipo de atividade na El favorece a adoção de uma abordagem sócio-pedagógica, que considera a interface entre natureza e sociedade, estando assim, em consonância com as Diretrizes Curriculares Nacionais para a Educação Infantil - DCNEI (BRASIL, 2010), que ao proporem o desenvolvimento das práticas pedagógicas, trazem orientações em conexão com o meio ambiente, no sentido de incentivar:

\footnotetext{
${ }^{5} \mathrm{KLEIN}$, Ângela. Educação Ambiental na Educação Infantil: um estudo de caso da Fazenda Quinta da Estância Grande - Viamão, RS, Universidade Federal de Santa Maria, 2007. Monografia apresentada como requisito para a obtenção do título de Especialista em Educação Ambiental.

${ }^{6}$ Os dados da análise foram obtidos pela pesquisa de campo realizada durante a primeira quinzena de outubro de 2006. Metodologicamente, utilizou-se a entrevista semi-estruturada com cinco monitores responsáveis pelo desenvolvimento das atividades educativas com as turmas de El e a observação direta, por meio do acompanhamento das turmas de crianças nesse período.
} 
[...] a curiosidade, a exploração, o encantamento, o questionamento, a indagação e o conhecimento das crianças em relação ao mundo físico e social, ao tempo e à natureza; [e] [...] - promovam a interação, o cuidado, a preservação e o conhecimento da biodiversidade e da sustentabilidade da vida na Terra, assim como o não desperdício dos recursos naturais (BRASIL, 2010, p. 26).

Possibilitar às crianças vivências nessa orientação, pressupõe um novo modo de sentir e pensar a vida e as relações com o mundo e, sob esse foco, apoiá-las a desenvolver o sentimento de identidade terrena e de compreensão humana, isto é, de se colocar no lugar do outro, em um processo de empatia, identificação, projeção e solidariedade humana - "[...] sempre intersubjetiva, a compreensão pede abertura [...] e generosidade [...]", o que implica o desenvolvimento de uma ética da compreensão, que é uma "arte de viver" de modo desinteressado (MORIN, 2000, p. 95 - 99).

Tais aspectos corroboram as reflexões decorrentes do segundo estudo, realizado em nível de Mestrado $^{7}$, o qual concentrou-se na análise das características de onze Propriedades Rurais Pedagógicas ${ }^{8}$, localizadas na região sul do Brasil. Os resultados da pesquisa evidenciaram várias atividades educativas desenvolvidas nas propriedades: - plantio e colheita de hortaliças e frutas (Sítio do Mato, Granja Santantonio, Sítio dos Herdeiros, Sítio do Tio Juca e Propriedade da Família Schroeder); - conhecimento acerca do mundo das abelhas (Apiário PFAU); - participação em oficinas de alimentação saudável (Propriedade Recanto das Pedras); - passeio ao Jardim dos Sentidos, com a pedra sussurrante, o labirinto dos sons e a pedra d'água (Agrícola da Ilha); realização de trilhas ecológicas (Agrícola da llha, Sítio do Mato, Vale das Nascentes); - passeio de carreta puxada por trator, atravessando rios e gramados (propriedade do Sr. Ango Kersten e Granja Santantonio); e visita ao museu rural (propriedade de Ango Kersten) (KLEIN, 2012).

\footnotetext{
${ }^{7}$ Mestrado, pela autora deste artigo, em Desenvolvimento Rural realizado no Programa de Pós-Graduação em Desenvolvimento Rural da Universidade Federal do Rio Grande do Sul e que resultou na elaboração da Dissertação: Turismo Rural Pedagógico e a Função educativa das propriedades rurais: uma análise a partir do Roteiro Caminhos Rurais de Porto Alegre-RS e do Projeto Viva Ciranda, Joinville -SC, defendida em 2012.

8 Foram analisadas seis propriedades rurais pedagógicas pertencentes ao Projeto 'Viva Ciranda', de Joinville, SC (Agrícola da Ilha, Propriedade da Família Schroeder, Sítio Vale das Nascentes, Apiário PFAU, CTG Chaparral e Propriedade do Senhor Ango Kersten); e cinco propriedades que fazem parte do Roteiro Caminhos Rurais de Porto Alegre, RS (Sítio do Tio Juca, Sítio dos Herdeiros, Sítio do Mato, Sítio Recanto das Pedras e Granja Santantonio). Na pesquisa de campo optou-se pela observação sistemática das atividades educativas e por entrevistas semiestruturadas, com onze proprietários e vinte e duas professoras responsáveis pelas turmas que visitavam esses espaços, entre julho e novembro de 2011.
} 
Além dessas atividades, as experiências em contato direto com animais (alimentar ovelhas, cabritos, bezerros, porcos, galinhas, peixes; segurar coelhos; tirar leite da vaca ou da cabra; passear a cavalo) foram identificadas em praticamente todas as propriedades analisadas; do mesmo modo que as atividades sensoriais de estímulo às percepções (inspirar e expirar o ar, ouvir o som dos pássaros e do rio, abraçar e sentir árvores, tocar e sentir a terra e a grama, sentir o cheiro das ervas medicinais, flores e frutos) e as brincadeiras recreativas (corridas, jogos com bolas, balançar-se nas árvores etc) (KLEIN, 2012).

Nesse sentido, reforça-se a compreensão de que as atividades realizadas pelas crianças nas Propriedades Rurais Pedagógicas permitemIhes uma série de experiências sensoriais e do relacionar-se com o outro e com o ambiente. Esse conjunto de aspectos revelam as potencialidades das Propriedades Rurais Pedagógicas, enquanto espaços favoráveis a uma Educação Ambiental crítica - responsável e comprometida com a sustentabilidade da vida, capaz de orientar e possibilitar e aos sujeitos:

\footnotetext{
[...] desenvolverem e redimensionarem valores, atitudes, hábitos e costumes cotidianos, em perspectiva de reconstrução das relações entre os seres humanos e, destes, com a natureza - de forma responsável, cidadã e sustentável, em busca de um maior equilíbrio local e global, atual e futuro (DICKMAN, 2015, p. 19).
}

Sob esse entendimento, emerge a possibilidade de reorientar as práticas pedagógicas no contexto escolar, desde a El, no sentido de promover a religação dos saberes, ou seja, substituindo o pensamento dicotômico, que separa, por um pensamento que une, conforme destaca Morin (2003), favorecendo, por conseguinte, uma El "[...] fundada na ética do cuidado, respeitadora da diversidade de culturas e da biodiversidade" (TIRIBA, 2010, p. 2).

No entanto, para que isso aconteça, é preciso superar alguns desafios que foram identificados, sobretudo na postura das professoras durante as visitas às propriedades rurais. Nas entrevistas realizadas com as mesmas, verificou-se um discurso que apontava questões relevantes relacionadas ao caráter educativo desses espaços; contudo, durante as atividades, nas propriedades, constatou-se uma posição passiva, de ouvintes, por parte 
dessas professoras. Não havia muitas intervenções no sentido de contextualizar e problematizar o que estavam vivenciando e, assim, possibilitar às crianças, no seu nível, um olhar criterioso sobre a realidade ambiente, quanto a aspectos sociais, políticos, econômicos e culturais - essenciais para uma EA crítica.

\section{Metodologia da Pesquisa de Campo}

O objetivo central da Tese, em construção, é desenvolver com as professoras da El uma práxis pedagógica em conexão com as Propriedades Rurais Pedagógicas, pautada em referenciais teórico-metodológicos da EA, sob o foco da cidadania socioambiental das crianças - o que requer a utilização de uma metodologia que possibilite o diálogo entre os participantes com vistas à criação de contextos reflexivos. Nesses termos, optou-se pela Pesquisa-Ação Colaborativa, por ser modalidade de investigação que tem como princípio a participação ativa dos sujeitos envolvidos na pesquisa (IBIAPINA, 2008). Como primeiro momento dessa pesquisa, foi realizado, no segundo semestre de 2017, um estudo exploratório envolvendo quatro Centros de Educação Infantil (CEIs), localizados no município de Joinville ${ }^{9}$, SC, que visitaram Propriedades Rurais Pedagógicas, neste período. O objetivo era o de verificar a ação pedagógico-didática das professoras de El durante as visitas a esses espaços, quanto à EA. As turmas observadas tinham entre 20 a 25 crianças, de 5 a 6 anos, acompanhadas de 2 a 4 professoras. As visitas de duas horas em média, ocorreram nas propriedades: Família Wiezbicki, localizada na Estrada Mildau; Recanto dos Pássaros, na Estrada Comprida; Sítio da Vó Bia, na Estrada Izack; e Agrícola da Ilha, no bairro Jardim Sofia.

\section{Educação Ambiental na Educação Infantil e Propriedades Rurais Pedagógicas: potencialidades e desafios}

\footnotetext{
9 A opção pelos Centros de Educação Infantil de Joinville justifica-se pelo fato de o município ser sede do Projeto Viva Ciranda, que atualmente conta com 13 Propriedades Rurais Pedagógicas, destacando-se como uma das poucas experiências no Brasil, envolvendo propriedades rurais e escolas. Dada a parceria entre a Secretaria da Educação Municipal de Joinville e o Projeto Viva Ciranda, diversas escolas municipais de ensino fundamental e Centros de Educação Infantil do Município têm realizado, no início de cada ano letivo, propostas de ensino e de aprendizagem, via projetos com visitas pedagógicas às propriedades rurais.
} 
A partir de observações e diálogos com as docentes das turmas dos quatro CEls, constatou-se a mesma posição passiva, já evidenciada na pesquisa de Mestrado. Durante os roteiros educativos, conduzidos pelos proprietários, foram observadas situações que envolvem questões socioambientais - contato com os animais e trilhas pelas matas ciliares, participação na confecção de biscoitos e até nas brincadeiras livres, no gramado - favoráveis ao desenvolvimento da EA. Nada, porém, foi problematizado pelas professoras. As preocupações concentraram-se nos aspectos comportamentais das crianças: "não gritem", "não empurra", "presta a atenção", "não mexa aí", "vai devagar", "não suba aí", "fiquem perto da profe", ou no registro fotográfico das situações, deixando de lado as possibilidades de reflexão problematizadora, em forma de perguntas dialogais, com as crianças, sobre o que estavam vivenciando.

Desse modo, percebe-se que as atividades nas Propriedades Rurais Pedagógicas são encaradas mais como um lazer, um passeio, uma recreação ao ar livre; e não como uma oportunidade concreta de ensino e de aprendizagem escolar, em um espaço profícuo para a EA. Da mesma forma, constatou-se uma visão ativista e conservacionista de Educação Ambiental. Em conversa com as professoras responsáveis pelas turmas, durante as visitas, verificou-se que a EA faz parte da rotina escolar na EI, a partir de projetos e atividades, como a horta escolar e a confecção de brinquedos e materiais com materiais recicláveis. Observou-se que a preocupação maior centrava-se no desenvolvimento de habilidades e comportamentos de conservação (não jogar lixo no chão, não desperdiçar água etc.), sem problematizar os fatos e situações - aspecto fundamental para que as crianças reflitam, segundo sua faixa etária, sobre sua realidade socioambiental.

Nesse contexto, destacam-se duas questões importantes sob o foco pedagógico: a primeira, relacionada à necessidade dessas docentes repensarem as atividades e experiências nas Propriedades Rurais Pedagógicas, em conexão com a Educação Ambiental, dado o valor desses espaços na conscientização socioambiental cidadã; e a segunda, referente às fragilidades e lacunas da prática de $E A$, especialmente, quanto à formação socioambiental cidadã das crianças. Segundo Guimarães (2012), 
é preciso reconhecer que na prática, a EA evidencia-se frágil, permeada por ações individualistas e descontextualizadas da realidade socioambiental em que as escolas se encontram situadas. Por conseguinte, a EA frequentemente tem sido reduzida a uma educação de caráter naturalista, atrelada a ações pedagógicas que não problematizam as questões sociais em conexão com a natureza e que, muitas vezes, apenas veiculam conhecimentos sobre o meio ambiente e dão pouca importância ao desenvolvimento de atitudes éticas, ao pensamento crítico e a ações criteriosamente competentes, pelos sujeitos envolvidos (SAUVÉ, 1999).

Sob essa perspectiva, a EA torna-se uma prática pedagógica descontextualizada, acrítica e ativista, que no olhar de Guimarães (2011, p. 2324), está vinculada a uma "armadilha paradigmática" do educador, ou seja, "[...] quando por uma 'limitação compreensiva e uma incapacidade discursiva (Viégas, 2002) ${ }^{10}$, o educador por estar atrelado a uma visão (paradigmática) fragmentária, simplista e reduzida da realidade, manifesta (inconscientemente) uma compreensão limitada da problemática ambiental [...]", tendendo a "[...] reproduzir o fazer pedagógico da educação tradicional, inebriando a perspectiva crítica e criativa no processo pedagógico, produzindo dominantemente na realidade escolar uma educação ambiental de caráter conservador" (GUIMARÃES, 2012, p. 124). Nessa linha, os docentes não questionam e não problematizam as causas dos problemas socioambientais, ocultando o conflito entre interesses privados e o bem coletivo e, dessa maneira, reforçando uma lógica hegemônica; essa EA, considerada conservadora volta-se a "[...] um processo educativo focado no indivíduo e na transformação de seu comportamento [...] não [visualizando] as práticas educativas como uma intervenção individual e coletiva no processo de transformações socioambientais" (GUIMARÃES, 2011, p. 26).

O desafio ao educador consiste, portanto, em superar essa "armadilha paradigmática", que condiciona e fragiliza a EA em todos os níveis de ensino, começando pela El. Um desafio associado à formação docente (inicial e continuada) e que implica, inevitavelmente, a conscientização sobre tais "armadilhas" e sobre a necessidade de romper com a visão fragmentada e

\footnotetext{
${ }^{10}$ VIÉGAS, Aline. Educação ambiental e complexidade: uma análise a partir do contexto escolar. Tese (Doutorado em Psicossociologia de Comunidades e Ecologia Social) - Programa EICOS, Instituto de Psicologia, Universidade Federal do Rio de Janeiro, Rio de Janeiro, 2010.
} 
antropocêntrica de mundo, ainda muito presente nas práticas pedagógicas das escolas. Para isso, é imperativo que os educadores atuem sob o foco da práxis pedagógica, no sentido de "[...] desenvolver e exercer uma liderança qualificada na construção de novas relações de reapropriação do mundo, em vista da formação de mentalidades compreensivas ante as complexas interrelações do meio [...]" (CARNEIRO, 2006, p. 18) - na perspectiva de uma Educação Ambiental crítica em oposição à conservacionista ou naturalista, centrada na dimensão ecológica - na preservação da flora e da fauna -, sem considerar as questões sociais.

\section{Considerações finais parciais}

As atividades educativas das Propriedades Rurais possibilitam às crianças uma experiência dos sentidos e de sensibilização para com a natureza, bem como possibilitando a compreensão das interdependências entre seres humanos e natureza. Nesse sentido, as Propriedades Rurais Pedagógicas emergem como espaços educativos potencializadores de uma Educação Ambiental crítica. Contudo, para que as atividades, nesses espaços, sejam significativas para as crianças, torna-se fundamental que as docentes atuem sob o foco de uma práxis pedagógica de planejar o trabalho escolar, com as Propriedades Rurais Pedagógicas, na linha de uma Educação Ambiental crítica e, desse modo, possam - antes, durante e após as visitas desenvolver a formação socioambiental cidadã das crianças. Tais desafios requerem, por conseguinte, o conhecimento e reconhecimento das potencialidades das Propriedades Rurais Pedagógicas, pela instituição escolar em conexão com a EA.

Do mesmo modo, torna-se imprescindível que as docentes conscientizem-se sobre as "armadilhas paradigmáticas" que conduzem suas práticas escolares, rompendo com a visão antropocêntrica de mundo e o pensamento fragmentado, em prol de um pensamento complexo, que una e religue os saberes (MORIN, 2000); assim como visando a uma educação humanista, crítica e transformadora, mediante uma prática socioambientalmente contextualizada, voltada à emancipação cidadã dos educandos (FREIRE, 1974; 2001; MORIN, 2015). 
A partir dessas reflexões, emerge uma provocação epistemológica, qual seja, a de desenvolver com as professoras da El - via a Pesquisa-Ação Colaborativa - uma práxis pedagógica em conexão com as Propriedades Rurais Pedagógicas, pautada em referenciais teórico-metodológicos da EA, sob o foco da cidadania socioambiental das crianças.

\section{Referências}

ABREU, Marise Jeudy Moura de. O diálogo da educação física com a educação ambiental na educação infantil: um processo de formação de docentes na rede municipal de ensino de Curitiba. Tese (Doutorado em Educação) - Programa de Pós-Graduação em Educação, Universidade Federal do Paraná, Curitiba, 2017.

BAMBI,Gianluca; TEI, Tiziana.; BARBARI Matteo. Linee guida per la progettazione, la realizzazione e la disciplina dell'attività di fattoria didattica. In: CONVEGNO NAZIONALE DELL'ASSOCIAZIONE ITALIANA DI INGEGNERIA AGRARIA, 9., 2009, Ischia Porto. Anais eletrônicos... Ischia Porto, 2009. Disponível em: http://atlanticmoon.com:8096/Agrisocialcoop/documentazione/agricoltura/29.LI NEE\%20GUIDA\%20FATTORIE\%20DIDATTICHE.pdf Acesso em: 20 set. 2017.

BRASIL. Ministério de Educação. Diretrizes Curriculares Nacionais para a Educação Infantil. Ministério da Educação. Secretaria de Educação Básica. Brasilia, DF: MEC; SEB, 2010.

CAFFARELLI, Júlia; COQUILLAUD, Marie-Sylvie.; DANIEL, Vicent.; THOU, Milène. Creér une ferme pédagogique: de l'idée à la realization. França: Educagri Editions, 2010.

CAMPOS, Andreia Sofia Pires Simões Ferreira de. Proposta de qualificação ambiental da Quinta Castanheiro da Areia. 2010. Dissertação (Mestrado em Engenharia do Ambiente) - Departamento de Ambiente e Ordenamento, Universidade de Aveiro, Aveiro, 2010.

CARNEIRO, Sônia Maria Marchiorato. A dimensão ambiental da educação escolar de 1‥ - 4a. Séries do ensino fundamental na rede escolar pública da cidade de Paranaguá. Tese (Curso de Doutorado em Meio Ambiente e Desenvolvimento - MADE), Universidade Federal do Paraná, Curitiba, 1999.

CARNEIRO, Sônia Maria Marchiorato. Fundamentos epistemo-metodológicos da educação ambiental. In.: Revista Educar, n...: 27, Curitiba, ed. UTRR, 2006. Disponível em:< https://revistas.ufpr.br/educar/article/view/6471/4660>. Acesso em: 03 fev. 2018.

DICKMANN, Ivo. A formação de educadores ambientais: contribuições de Paulo Freire. 2015. Tese (Doutorado em Educação) - Programa de PósGraduação em Educação, Universidade Federal do Paraná, Curitiba. 2015. 
FRANCO, Silvio.; SENNI, Saverio. (Ed.). La funzione sociale dell'agricoltura: II caso del Lazio. [S.I.]: Università della Tuscia, 2005. (Quaderno ISE, n. 15). Disponível em < www.grupponoise.it/files/doc02.pdf> Acesso em: 30 jul. 2018.

FREIRE, Paulo. Pedagogia do oprimido. Rio de Janeiro: Paz e Terra, 1974.

FREIRE, Paulo. Pedagogia da autonomia. 18 ed. Rio de Janeiro: Paz e Terra, 2001.

GUIMARÃES, Mauro. Armadilha paradigmática na educação ambiental. In: LOUREIRO, C.F.B.; LAYRARGUES, P. P.; CASTRO, R. S. (Orgs.). Pensamento complexo, dialética e educação ambiental. 2 ed. São Paulo: Cortez, 2011. p.11-29.

GUIMARÃES, Mauro. A formação de educadores ambientais. 8. ed. Campinas, SP: Papirus, 2012.

GURRIERI Carmelo. Scuola in Fattoria: dal produttore al consumatore verso un consumo consapevole. In: LA RETE delle aziende e delle fattorie didattiche in Sicilia: la documentazione dell'esperienza. Palermo: ARPA Sicilia, 2008. v. 2. Disponível em: <www.arpa.sicilia.it/UploadDocs/1369_Fattorie_Didattiche.pdf >. Acesso em: 15 mar. 2018.

JOLLY, Linda, et al. The Farm as a Pedagogical Resource: background for and evaluation of the co-operation between agriculture and primary school in the county of Nord-Trondelag, Norway. IN: SIXTH EUROPEAN IFSA SYMPOSIUM, 2004, Portugal. Proceedings of the Sixth European IFSA Symposium: Farming and Rural Systems - Research and Extension. Vila Real, Portugal: UTAD, 2004. p. 497-507.

KLEIN, Angela Luciane. Educação Ambiental na Educação Infantil: um estudo de caso na Fazenda Quinta da Estância Grande- Viamão/RS. Monografia (Especialização e Educação Ambiental). Programa de PósGraduação em Educação Ambiental. Universidade Federal de Santa Maria, Santa Maria, 2007.

KLEIN, Angela Luciane; TROIAN, Alessandra.; SOUZA, Marcelino. O turismo rural pedagógico e a educação ambiental: as ações pedagógicas desenvolvidas na fazenda quinta da estância grande Viamão (RS). Revista Eletrônica do Mestrado em Educação Ambiental, v. 27, p. 107-121, 2011. Disponível em: <http://www.remea.furg.br/edicoes/vol27/art8v27.pdf >. Acesso em: 20 jun. 2018.

KLEIN, Angela Luciane. Turismo rural pedagógico e a função educativa das propriedades rurais: uma análise a partir do roteiro caminhos rurais de Porto Alegre-RS e do projeto viva ciranda, Joinville-SC. Dissertação (Mestrado em Desenvolvimento Rural) - Programa de Pós-Graduação em Desenvolvimento Rural, Universidade Federal do Rio Grande do Sul, Porto Alegre, 2012.

NASOLINI, Tiziana. Educare all'ambiente e all'alimentazione. In: BERTOLINI, S. (Ed.). Nuovi educatori ambientali: Esperienze seminariali nel Master in 
Educazione Ambientale. V. 4, Bologna: Regione Emilia-Romagna, 2005. p. 233- 239. Disponível em < https://www.regione.emiliaromagna.it/infeas/documenti/pubblicazioni/quaderni/quaderno4>. Acesso em: 20 jul. 2018.

MORIN, Edgar. Os Sete Saberes Necessários à Educação do Futuro. São Paulo: Cortez, 2000.

MORIN, Edgar. A cabeça bem-feita: repensar a reforma, reformar o pensamento. Tradução Eloá Jacobina. 8. ed. -Rio de Janeiro: Bertrand Brasil, 2003.

MORIN, Edgar. Ensinar a viver: manifesto para mudar a educação. Trad. Edgard de Assis Carvalho e Mariza Perassi Bosco. Porto Alegre: Sulina, 2015.

SAHEB, Daniele. A Educação Ambiental na Educação Infantil. Revista Eletrônica do Mestrado em Educação Ambiental, v. 1, p. 133-158, 2016. Disponível em:< https://periodicos.furg.br/remea/article/view/5439>. Acesso em: 04 mar. 2018.

SAUVÉ, Lucie. La Educación Ambiental entre la modernidade y la postmodernidade: en busca de un marco de referncia educativo integrador. Tópicos en Educación Ambiental, v. 1, n. 2, p. 7-25, 1999.

SAUVÉ, Lucie. Educação Ambiental: possibilidades e limitações. Educação e Pesquisa, São Paulo, v. 31, n. 2, p. 317-322, maio/ago. 2005. Disponível em: http://www.scielo.br/pdf/\%0D/ep/v31n2/a12v31n2.pdf. Acesso em: 19 abr. 2018.

TIRIBA, Léa. Reinventando relações entre seres humanos e natureza nos Espaços de Educação Infantil. In: Soraia Silva de Mello; Rachel Trajber. (Org.). Vamos Cuidar do Brasil - Conceitos e Práticas em Educação Ambiental na Escola. 1 ed. Brasília: MEC, 2007, p. 219-228.

TIRIBA, Léa. Crianças da Natureza. In: Consulta Pública, Ministério da Educação e do Desporto. Coordenadoria de Educação Infantil. Brasília: MEC/SEF, 2010. Disponível em:< http://portal.mec.gov.br/index.php?option=com docman\&task=doc download\& gid=6679\&ltemid $=>$ Acesso em: 20 nov. 2017. 